\title{
Partnership among Librarians: Reflection on Observations, Interviews and Research Reports from Three Universities in Nigeria and Zimbabwe
}

\author{
Rexwhite T. Enakrire ${ }^{1}$, Collence T. Chisita ${ }^{2} \&$ Tella Adeyinka ${ }^{3}$ \\ Department of Information Science, University of South Africa, Pretoria, South Africa. \\ Correspondence: Rexwhite T. Enakrire, Department of Information Science, University of South Africa, Pretoria, \\ South Africa.
}

Received: May 28, 2020

Accepted: August 14, 2020

Online Published: August 17, 2020

doi:10.5430/ijhe.v9n5p338

URL: https://doi.org/10.5430/ijhe.v9n5p338

\begin{abstract}
Partnership is not a new phenomenon in the university environment. It embraces strategies used by people with common interest to harvest knowledge in terms of sharing or collaboration. However, the case differs with collaborations in Library and Information Science (LIS) research in Africa, especially LIS scholars in African universities in Nigeria and Zimbabwe. Paucity of empirical literature is available on research collaboration among LIS scholars in Nigerian and Zimbabwean universities. The purpose of the study was to examine partnership among librarians, with reflection on observation and interview research reports in three universities in Nigeria and Zimbabwe. The study adopted a qualitative approach using interview to gather data from librarians drawn from three Nigerian and Zimbabwean universities. The qualitative research approach grounded on content analysis of documents/literature, observation and interview method was use for the study. The observation focus on the authors' exposition in the sampled universities environment, while the interview were key informants from each of the three countries universities sampled. The study consider the collaborative theory through grounded method. The findings of the study revealed lack of trust in the individual or groups collaborator; team members have the feeling that the project they are collaborating on is of little benefit, due to poor relationship. Team members see themselves as contender or challenger; which has affected leadership issue and involvement of long meetings and inability to address the truth. In terms of the influence of collaboration on professional growth of librarians, result demonstrated enhancement of teaching aspect of librarianship, learning and research quality; promote cooperation, coordination, which in turn increased level of intensity, tenacity and interaction among members. Linkage among LIS professional ranges from networking, cooperation, alliances, coordination and partnership, coalition and eventually collaboration. Challenges reported include catastrophic consequent on negative effect of work, culture and stylistic parameters including concept, attitude and professional hindrances. dominance impact of policies and procedures of collaboration, exploitation of the weak members, lack of clarity and rationale behind the collaboration, unwillingness to change by members in collaboration, lack of socialisation, largeness of the group, wrong membership and jettisoning of members ideas which eventually make some members take the decision of quitting the team. The study recommends inter-disciplinary, intra-institutional and inter-institutional collaboration among various stakeholders in LIS education and training.
\end{abstract}

Keywords: collaboration, cooperation, partnership, knowledge sharing, librarians, strategies, university environment, Nigeria and Zimbabwe

\section{Introduction and Conceptual Background}

This study which investigates partnership among librarians with reflective observation and interview in three Universities in Nigeria and Zimbabwe was divided into three sections. The first section considered general or broad overview of partnership or collaboration among librarians. The second section focused on the problem or issues that necessitate the study, while the third section detailed the objectives of the study.

Collaboration in research is now commonplace particularly among academics in universities worldwide. The revolution brought by ICT, which has turn, the whole world into a global village, making it possible for academics to collaborate with colleagues anywhere in the world. The term 'collaboration' is used to depict all forms of agreement between academic institutions, corporate organisation, universities, and any combination of two or more parties, where information and knowledge share (Tella, Akinboro \& Hammed, 2012). The commitment to reach a common goal by using their available resources are key factors in the interplay (Tella, Akinboro \& Hammed, 2012). 
Collaborations among researchers can take many forms. In a sense, there is a continuum ranging from the classic partnership between two faculty members at academic institutions, to situations such as the use by one researcher of another's resources such as a piece of equipment, a biological strain, or a database.

Adams (2012) opines that networks of research collaboration are expanding in every region of the world. The author argues that such developments are likely to challenge the status quo concerning knowledge production as the levellers of intellectual power shift from the Atlantic axis. Adams (2012) highlights the rise of novel regional networks that are reinforcing the competence and capacity of emerging research economies, and changing the global balance of research activity. Adams (2006) further notes that, knowledge could be transferred and combined better, when collaboration and co-authored papers are cited more frequently. Adams (2012) views co-authorship as a valid proxy for collaboration because few scientists surrender credit for their papers lightly, so we can assume that sharing of authorship reflects a tangible engagement.

Siyao, Whong, Martin-Yeboah and Namamonde (2017, 242-255) state that despite the numerous intellectual activities that are happening in Africa, only $2 \%$ of global research output is attributable to the continent. This declining trend makes the countries which lie south of the Sahara Desert, commonly known as Sub-Saharan Africa countries (SSA), to account for less than 1\% of the world's research output (World Banka and Elsevier, 2014). Research collaboration provides an opportunity for researchers in Africa to claim their space in the intellectual landscape of global knowledge production. The market share of monopoly capitalism has seen fifty percent of scholarly publications being controlled by a group of five publishers thus making it difficult for libraries, researchers and scientists failing to meet subscriptions to the scholarly literature they needed for research and teaching (Chan, 2004). Macdonald (2015) argues that the predatory nature of such oligopolistic and monopolistic tendency is no longer helpful to scientists and researchers who need to advance knowledge. The dialectical relationship between publisher and researcher or scholars has provided a fertile ground to critique and change exploitative models of publishing so that scientists and researchers will have affordable and sustainable access to their content. Furthermore, the author notes that as research becomes more data intensive, a scholar's ability to store, access and share primary data will be crucial to the advancement of scholarship.

Ocholla (2008, 466-479) cites Ecosystem Management Initiative (2002) which describes collaboration as a "process where two or more individuals or organizations deal collectively with issues that they cannot solve individually". Relative to this, Albert (2009) describes collaboration as the pooling of resources by two or more stakeholders or partners to solve a problem that neither can solve individually. The author also views collaboration as a "partnership, alliance or network, aimed at a mutually beneficial clearly defined outcome" (Commonwealth of Australia, 2004, 1).

As indicated by Ocholla (2008, 446-479), collaboration takes many forms. This ranges from interpersonal; inter-group; inter-departmental, intra-departmental; intra institutional, inter-institutional; within sectors, inter-sectoral; countries-national/international; or regional/inter-regional. The emphasis made by Ocholla $(2008,466-479)$ in recommendation of collaboration and partnerships amongst LIS institutions are at the local and international levels in the area of research. Lee and Bozeman (2005) assert that, the impact of research collaboration in scientific productivity are quite high. Lee and Bozeman (2005, 673-702) placed emphasis on research collaboration that has been widely discussed in bibliometric studies over the past decades. The definition made by Katz and Martin (1997) on research partnership among researchers implies working together to achieve common goal of producing new scientific knowledge. Lee and Bozeman (2005, 673-702), Hauptman (2005) and Bammer (2008) and Eaton, Ward, Kumar and Reingen (1999) and Ponomariov and Boardman (2010) argue that, in research partnership/ collaboration is of great significance to researchers. It helps scholars to share their workloads, experiences, specific expertise and particular skills, which could become resources, for fresh ideas, and possibly increase, research output of academics. Ardanuy (2012, 877-890) highlights the numerous research collaboration and networking in science, which for example, allows researchers to share techniques, facilitates knowledge sharing and transfer, contribute to the screening and development of new ideas. Ardanury, $(2012,877-890)$ argue further that research partnership also promotes intellectual esprit de corps and networks the researcher to participate in a wider network of contacts within the scientific community. Scientific collaboration helps accelerate problem solving, stimulates creativity, and enhances interdisciplinary, avoiding rigid intellectual insularity (Ardanuy, 2012, 877-890, Rijnsoever, Hessels, \& Vandeberg 2008, 1255-1266 and Chisita and Abdullahi, (2012.1-16).

Chang (2009) and Yan, Ding, and Zhu (2010,115-131) note that despite the lack of substantial evidence of studies on collaboration in LIS in Africa, there was however a significant evidence on recent Asian researchers enhancing their influence and moving toward internationalization significantly with an increase in the frequency of international co-authorship. Hallam, and Partridge (2006:1-3) argue that the LIS professionals is supposed to engage in continuous 
research in order to create new knowledge and contribute towards the growth of LIS as a profession or discipline. Gibbons (2005) states that, academic institutions can only serve the public and justify their existence, through funding by taxpayer, thus producing "socially robust knowledge." This knowledge requires inter-disciplinary, intra-institutional and inter-institutional collaboration between various stakeholders in LIS education and training.

\section{Research Problem}

Previous studies by Lee and Bozeman (2005), Hauptman (2005), Bammer (2008) and Ponomariov and Boardman (2010) emphasised that, partnership is an indispensable enterprises which academic professionals, specifically librarians cannot be deprive of, in this era of digital technology. The digital technology era requires that research collaboration/knowledge sharing becomes a routine. This attribute to useful insights, which researchers gain when they integrate with one another through different platform. Partnership with fellow colleagues has made workloads more lessened, considering experiences of certain individual expertise. The expertise is grounded on skills, fresh knowledge/ideas, which grows on daily basis through research output and citations of people's work. The first author of this paper, based on his experience and observation having attended several international conferences and training programmes in Nigeria, Kenya and specifically South Africa noticed that most librarians do not integrate fully into partnership with their fellow colleagues. This claim was based on the observation made from those who presented their research papers in the conferences attended during a conference attended in the three mentioned countries. It was observe after scanning through the programmes and listening to several individuals, notice that, majority of presenters papers were solely lecturers.

The authors believed that librarians, considering their roles and position as academic staff in any university environment are expected to be deeply rooted in research partnership. The reason behind this is that, librarians as academic staff should partners with other colleagues in different research projects, publication of articles and even teaching related courses on the use of libraries and their resources to newly admitted students and especially postgraduate students who are deeply involved in research activities require more support in the university environment. The essence of why partnership and collaboration among librarians is significant is that, it will foster how the librarians could go extra mile in harvesting information and data that would support both the undergraduates, postgraduate and other researchers, within the universities. These practices would broaden librarians' horizon in library operations and practices. However, in most of the countries universities mentioned-Nigeria, Kenya and South Africa, observation by the researchers revealed that such practices among librarians are limited. The authors envisage that, the organisational culture do not encourage librarians to be much involved in this practices. Some librarians are lazy to partner, thus reflecting on the enormous task it takes to write a research paper. Besides, other complains were time factors, inability to work with team, pride in associating with others and enormous work responsibility which librarians are saddle with, were believe to affect partnership among librarians. Writing skills and knowledge of research activities was also envisage on why librarians do not partners with other colleagues. In most of the institutions in Africa, no stipulated policy, that addresses compulsory partnership among librarians. Another point of emphasis is the drive or willingness among librarians. For instances, if librarians are willing to partners but do not have the right set of class or those with the same mind-set, partnership becomes discouraging. Partnership requires two individual who are willing and have the same drive towards a specific goals or project before partnership can work effectively. Some of the librarians who have partnered/collaborated with one another was on personal effort and consistency of their motives in the university environment.

Collaboration in research has been a broadly exploited and used phenomenon for many years in various disciplines around the world; especially in the developed countries such as UK, Canada, Europe and America. However, the case differs with reference to collaboration in Library and Information Science (LIS) research in Africa, among LIS scholars in African universities, particularly Nigeria and Zimbabwe. Limited empirical literature is available on research collaboration among LIS scholars in Nigerian and Zimbabwean universities. It is against these backdrops that this study examined Nigerian and Zimbabwean LIS scholars' perception of the partnership and collaboration in LIS research.

\section{Objectives of the Study}

The main objective of the study is to investigate partnership among librarians, with reflection on observation and interview research reports in three universities in Nigeria and Zimbabwe. In line with this, the specific objectives of the study are to: 
1. Examine why librarians do not partners with one another in Universities in Nigeria and Zimbabwe

2. Examine how partnership with other librarians influence professional growth, and;

3. Find out challenges that interface with partnership among librarians.

\section{Literature Review}

For growth and career development, academics today are expected to engage in partnership and collaboration in research and other academic activities. Definitions abound on partnership. This is because experts look at the concept based on their individual perception. Partnership can simply be referred to as an association of two or more persons as partners. Hagedoorn et al. (2000), defined partnership as an innovation-based relationship that involves, partly a significant effort in research and development. As mentioned earlier, partnership could be formed to achieve research goal. Therefore, research partnership is seen as mechanism that enable partners to learn new ideas, and pool resources together in the pursuit of some laudable objectives. Collaboration on the other hand, is a working practice where individuals (partners) work together to a common purpose to achieve benefits (Tella et al., 2012). It can be referred to as a process where group of people come together and contribute their expertise for the benefit of a shared objective, project, or mission. In other words, it is the process of group work, a leaned skills and how well partners collaborate with other will greatly impact the outcome of the group project. In collaboration, academics or librarians work together alongside others to constructively explore ideas, discover new solutions and explore unique though processes. Ultimately, the end results of collaboration is to accomplish something as a team, it may be completing a research project or working together to solve a particular identified problem.

Partnership or collaboration in academic particularly among librarians is important. From the literature, partnership and collaboration is considered important based on the need to solve research problem, bring people (members) i.e. academics together, enables academic to learn from one another, open up new channels for communication, assists in boosting morale of members, leads to higher retention rates, and makes academic more efficient in their career (Tella et al., 2012).

However, despite the importance of collaboration, literature has also revealed that some people (academics/librarians) dislike or detest collaboration. Why is this so? According to the literature, several reasons abound why people don't want to collaborate. Walker (2015) identified lack of trust, fear of minimisation and losing control. Similarly, McDonald (2015) averred that people don't collaborate due to fear of being wrong, because they feel ignored, unconsciously competent, because their colleagues don't share with them, and because they lack the skills. Irrespective of the reasons why academics or librarians don't collaborate, collaboration is important and all academics of which librarians are inclusive must always take part. This study dogged dipper in term of reflecting on partnership among librarians through observation and interview from three universities in Nigeria and Zimbabwe.

\section{Theoretical Background}

Theories abound on collaboration and partnership among professionals. This study has identified an interpersonal theory of collaboration. It refers to how collaboration works irrespective of whether the former structure is between managers and subordinate, subordinate with subordinate, or some other permutation. This differs from leadership theories such as leader-member exchange (LMX) in a number of respects. The theory assumed that both members of the vertical dyad become the foci of investigation in the leadership process and that both members have active relationship power, it treats power as concentrated in the manager role. Much collaboration, on the other hand, involves groups without a hierarchical authority structure. For these reasons and more, including differences in intent, in our research method in this study, applied collaborative theory along with grounded theory. Grounded theory was used, where collaboration is defined as any ongoing interpersonal interaction not characterized by a significant power imbalance with the express purpose of achieving common goals. The goal of a grounded approach as a research method is to generate a theory or model from data through rigorous systematics approach/ Grounded theory employs qualitative research procedure as emphasised by (Creswell, 2013). This is in line with the qualitative approach employed in this study.

\section{Methodology}

The qualitative research approach was the partway followed in this research paper. The qualitative approach was grounded on interpretive content analysis of documents/literature and interview and observation. The interpretive content analysis of documents harvested literature from databases in Scopus and Science direct on the chosen topic. Interview was conducted telephonically across six key informants in each of the three universities in Nigeria (Delta State University DSU, Federal University of Petroleum Resources-FUPRE and Novena University, Ogume, Kwale and Zimbabwe (University of Zimbabwe -UZ, Bindura University of Science Education-BUSE and National 
University of Science and Technology-NUST). While the observation method was grounded on the researchers' exposition in knowledge concerning the environment sampled for this study. The responses from interview reports and researchers observation were collated in sequence according to the research objectives of the study. The findings from the interviewed key informants and observation were presented in informative manner as they were extracted from key informants.

\section{Results}

This segment dwells on the result of the sub-themes that was presented in objectives of the study. The results were in line with reports from key informants obtained from the two countries universities librarians. These were presented below.

\subsection{Why Librarians do not Partners with one Another in Universities}

In this section, respondents were asked to indicate why they do not partners with one another in their universities. From the responses gotten from the respondents, LIS researchers do not collaborate because often times there is the issue of lack of trust in the individual or groups collaborators. Sometimes, as posited by some of the respondents' members of team sometime feel that the project they are collaborating on is of little benefit to them. This was due to poor interpersonal relationship among team members, which implies little or no conversation among participating team members. It was notice that, poor relationship results when teams see themselves as contender or challenger, rather than partners in progress or perhaps not giving in to new ideas or suggestions by others. Similarly, the results indicate that working in a group for the first time means so much. This is because the group members will have to take their time in studying one another because there are difference in personality. As one respondents emphasised "oftentimes, it is difficult resolving an initial growing problem, and failure to acknowledge and solve such problems might obstruct or hinder collaboration thereby causing conflict, disagreement and disunity among members thereby retard the outcomes". Establishing and putting up relations enable ideas, innovation and creativity to flourish thereby collaboration is encouraged and stimulated. However, the absence of all these lead to defeat of the essence of the whole process.

One of the respondent has this to say, "the issue of members having some mind-sets whereby there is acceptance of a prevailing idea without allowing other members especially, new ones to partake in the discussion usually discourage colleagues from participating in coloration". This should not always be the case. Once a member of a collaborative team, have the opportunity of asking questions, or query an existing condition or phenomenon, should always be allowed. But the fact is that, the reverse is always the case, in as much as why many people do not want to collaborate, the effort will be thwarted. It was also gathered from the respondents that LIS scholars do not want to collaborate because some usually find it difficult to talk or express their thought especially in public space and this cause them to now dis-member themselves from the group.

The respondents also expressed the view that, leadership issue sometimes discourage them from participation in collaboration. They explained that when it comes to maximising the efficiency of team collaboration, although leadership is very essential. However, some team members instantly look to their leaders for leading and instructions waiting for feedback to further action. So many leaders according to their report deter their team from achieving their motive. A respondent added that, "it is discouraging when leaders do not appreciate or reward progress made when leading, failing to understand that reward or praise boost team morale and let the members have the feelings that they are on the right track" Some respondents also mentioned that they did not like participating in collaboration because it usually involves long meetings. In fact, two respondents from both countries emphatically point out "I don't have time to waste.....siting for long hour in the name of collaboration is already out of my way" Seriously speaking, when meetings last too long and does not have focus, it cause team members to lose interest and sometimes feel bored. The decrease productivity can even reduce membership morale thereby hindering successful team collaboration. There is also a reflection from the data gathered that some LIS scholars do not like to partner because of the inability of most groups to address the truth. To buttress this, a respondent mentioned that "if team members can learn how to be honest and push each other to struggle for tangible results, improving themselves personally and members of the team, will be appreciated and beneficial to them all".

\subsection{How Partnership with other Librarians has Influenced Professional Growth}

Librarians testified on how partnership with other colleagues has influenced their professional growth in their various universities. The common saying now is that, the future of professional development is collaboration. There are number of benefits and advantages associated with collaboration. This may include enhancement of the teaching aspect of librarianship, learning and research quality. From the respondents, it was gather that collaboration helps closes the 
gaps between teaching and research in LIS, enhances the quality of teaching and learning activities in LIS, discourage isolation and encourage collective actions by LIS scholars. Similarly, it advances curriculum innovation, review and reform, enriches learning experiences and develops lifelong learning skills among librarians and LIS students.

It was notice from the findings that, collaboration relationship among LIS scholar promote cooperation, and coordination. Importantly, representation of increased level of intensity, tenacity and interaction among members is ensured when librarians partners and collaborate. Linking this result to LIS professional, ranges of activities such as networking, cooperation, alliances, coordination and partnership, coalition and eventually collaboration is optimum. Oftentimes, collaboration in LIS reflect the major aims of librarians in the process of developing and fully integrating information literacy programs with the course program to enhance student learning.

\subsection{Challenges that Interface with Partnership among Librarians in Universities}

The challenges, which librarians encountered during the partnership period, were highlighted and the results presented below. Collaboration is good and is accepted worldwide, although a complex concept which constitute high-level human relationship and with many potential obstacles towards developing it. As evident from the findings in this research, it was confirm by the respondents that, there are manifestation of different obstacles and hindrances to collaboration in LIS. It was confirm by the respondents that partnership could be catastrophic consequent on the negative effect of work, culture and stylistic parameters including concept, attitude and professional hindrances.

It was also confirm that a number of challenges eminent in collaborative effort in the bid to achieve common goal. These according to the respondents range from building reciprocal trust, respect and commitment amongst different groups. The dominance impact of policies and procedures of collaboration was identified by respondents as challenges that may hinder the partnership and the way librarians work together. One respondent put it this way "achieving original partnership may be a daunting task where a party of the partnership felt that their function and contribution were being taken over". The respondent goes further to mention that "power, identify, influence and integrity are common issues in librarians collaboration with different partners. The respondent gave an instance of the possibility where a lower status party might excessively be exploited, when partners are pursuing their professional advancement. So, also it was explained by the respondent that, individual factors such as personality and attitude are significant issues in collaboration.

Other prominent challenges identified by the respondents are lack of clarity and rationale behind the collaboration, unwillingness to change by members in collaboration, lack of socialisation, largeness of the group, wrong membership and jettisoning of members ideas which eventually make some members take the decision of quitting the team,.

\section{Discussion}

This study has examined partnership among librarians, with reflection on observation and interview research reports from three universities in Nigeria and Zimbabwe. The study revealed that librarians do not want to participate in collaboration due to lack of trust in the individual or groups collaborators; team members have the feelings that the project they are collaborating on is of little benefit due to poor relationship. Some teams see themselves as contender or challenger, which in turn result to leadership issue, and when involved, most of the time-spent meetings are too long and inability to address the truth was notice. The result here correspond with Tella et al. (2012) and Yousef (2010) reports, which affirms that, some LIS researchers', have not been taking part in the research collaboration.

In terms of the influences of collaboration on professional growth among librarians, result demonstrated showed enhancement of teaching aspect of librarianship, learning and research quality; promote cooperation, coordination. Interesting, representation of increased level of intensity, tenacity and interaction among members was based on their ability to partner and collaborate. Although, link to partnership among LIS professional brought networking, cooperation, alliances, coordination and coalition and eventually collaboration. This finding relates with Pham and Tanner (2015) report, which indicate that collaboration among librarians facilitate access and enables provision of more discipline-relevant resources to students and greater enhancement of their academic skills. Tella et al. (2012) also attest to finding that indicate, collaboration usually portray the image of LIS profession in the country just like other professions. It showcase how the profession are faring in terms of overall contribution to the development of the profession globally; and create awareness on the part of those who have limited knowledge on how collaborative research is done.

Challenges reported include catastrophic consequent on the negative effect of the work, culture and stylistic parameters including concept, attitude and professional hindrances. Dominance impact of policies and procedures of collaboration, exploitation of weak members, lack of clarity and rationale behind the collaboration, unwillingness to change by members in collaboration, lack of socialisation, largeness of the group, wrong membership and jettisoning 
of members ideas which eventually make some members take the decision of quitting the team. There is no doubt that when people gather in team, problems will also erupt, but the expectation is that, problem can always be manage. Naturally, this is bound to happen. Therefore, this finding corroborate the report by Chibozor et al. (2017) and Yu-Wei (2019) who identified challenges of collaboration to include lack of fund, limited technological infrastructure, time factor; difficulty in working with colleagues in research, and fear of non-contributions by others among others. Similarly, the report by Pham and Tanner (2015) who identified dimensions of time, space and individual factors as they impact partnerships buttress the current finding in this study.

\section{Conclusion}

The study examine partnership among librarians, with reflections on observation and interview research reports from three universities in Nigeria and Zimbabwe. The findings of the study revealed lack of trust among individual or groups collaborators. Team members have the feeling that the project they are collaborating on is of little benefit, due to poor relationship. Some team members see themselves as contender or challengers. Leadership issue; involvement of long meetings and inability to address the truth, was considered. In terms of the influence of collaboration on professional growth among librarians, result demonstrated enhancement of teaching aspect of librarianship, learning and research quality; promotion of cooperation, coordination. These are usually represented by increased level of intensity, tenacity and interaction among members; and linkage among LIS professional ranging from networking, cooperation, alliances, coordination and partnership, coalition and eventually collaboration. Challenges reported include catastrophic consequent on the negative effect of the work, culture and stylistic parameters including concept, attitude and professional hindrances. Dominance impact of policies and procedures of collaboration, exploitation of weak members, lack of clarity and rationale behind the collaboration, unwillingness to changes by members in collaboration, lack of socialisation, largeness of the group, wrong membership and jettisoning of members ideas could eventually make some members take the decision of quitting the team.

\section{Recommendations}

Based on the findings of this study, the following recommendations were made: There is need to encourage and educate each member of the research group through teaching directing and correcting them to ensure they are carried along with the skills in research writing. This calls for having cordial interactions. It is important for the librarians to have an understanding that collaboration is characterised by respect for each team members' knowledge, skills and expertise and recognising the other profession as an equal partner, with different but complementary skills. Librarians when planning for collaboration should always involve the selection of competent individuals who have well developed interpersonal skills and personalities that mesh, and choice of a subset of subjects/curriculum areas with the greatest potential for successful outcomes.

\section{References}

Adams, J. (2006). International Partnerships of Research Excellence (ed. Roberts, G.). Retrieved from: http://go.nature.com/zzwn8z.

Adams, J. (2012). Collaborations: The rise of research networks. Nature, 490(7420), 335. https://doi.org/10.1038/490335a

Albert, S. (2009). Networked Communities: Strategies for Digital Collaboration: Strategies for Digital Collaboration. IGI Global. https://doi.org/10.4018/978-1-59904-771-3

Alves, J. \& Meneses, R., (2018). SILOS MENTALITY IN HEALTHCARE SERVICES. In 11th Annual Conference of the EuroMed Academy of Business.

Ardanuy, J., (2012). Scientific collaboration in Library and Information Science viewed through the Web of Knowledge: the Spanish case. Scientometrics, 90(3), 877-890. https://doi.org/10.1007/s11192-011-0552-1

Chan, (2004). Supporting and enhancing Scholarship in the digital age: Role of Open access Institutional repositories. Canadian Journal of Communication, 29(3), Retrieved from https://www.cjc-online.ca/index.php/journal/article/view/1455/1579 https://doi.org/10.22230/cjc.2004v29n3a1455

Chang, H.-W. (2009). A bibliometric analysis of Asian authorship pattern in JASIST 1981-2005. In Asia-Pacific conference on library \& information education \& practice. Tsukuba: Japan University of Tsukuba. http://www.slis.tsukuba.ac.jp/ atsushi/a-liep/proceedings/Papers/a31.pdf. Accessed 6 May 2011. 
Chibuzor, L.D., Ukwoma, S; \& Nwamaka, O.V. (2017). Perception of librarians towards collaborative research in academic libraries in Nigerian Universities. Library Philosophy and Practice (e-journal). 1596. http://digitalcommons.unl.edu/libphilprac/1596

Chisita, C.T. \& Abdullahi, I. (2012). Rising above the grain Silo mentality through collaboration: creating opportunities between the LIS educators and practionners in Developing Countries. In World Library and Information Congress: 78th IFLA General Conference and Assembly. Helsinki: IFLA, 1-16.

Creswell, J. W. (2013). Qualitative inquiry \& research design (3rd ed.). Los Angeles, CA: Sage.

Eaton, J. P., Ward, J. C., Kumar, A. \& Reingen, P. H. (1999). Structural analysis of co-author relationships and author productivity in selected outlets for consumer behaviour research. Journal of Consumer Psychology, 8(1), 39-59. https://doi.org/10.1207/s15327663jcp0801_02

Hagedoorn, J.V, Link, N.A. \& Vonortas, N.S. (2000). Research partnership. Research Policy, 29(2), 567-586. https://doi.org/10.1016/S0048-7333(99)00090-6

Hauptman, R. (2005). How to be a successful scholar: Publish efficiently. Journal of Scholarly Publishing, 36(2), 115-119. https://doi.org/10.3138/jsp.36.2.115

Lee, S. \& Bozeman, B. (2005). The impact of research collaboration on scientific productivity. Social Studies of Science, 35(5), 673-702. https://doi.org/10.1177/0306312705052359

Ocholla, D.N., 2008. The current status and challenges of collaboration in library and information studies (LIS) education and training in Africa. New library world, 109(9/10), 466-479. https://doi.org/10.1108/03074800810910496

Pham, H.T. \& Tanner, K. (2015) Collaboration Between Academics and Library Staff: A Structurationist Perspective. Australian Academic \& Research Libraries, 46(1), 2-18. https://www.tandfonline.com/doi/pdf/10.1080/00048623.2014.989661

Rijnsoever, F., Hessels, L., \& Vandeberg, R. L. J. (2008). A resource-based view on the interactions of university researchers. Research Policy, 37(8), 1255-1266. https://doi.org/10.1016/j.respol.2008.04.020

Siyao, P.O., Whong, F.M., Martin-Yeboah, E. \& Namamonde, A. (2017). Academic libraries in four Sub-Saharan Africa countries and their role in propagating open science. IFLA journal, 43(3), $242-255$. https://doi.org/10.1177/0340035217712263

Tella, A., Akinboro, E., \& Hammed, S.T. (2012). The Perspective of LIS Scholars/Researchers on the Impact of Collaboration in LIS Research in the Digital Age. Paper Presented during the $50^{\text {th }}$ NLA Conference, Abuja.

Vatanpour, H., Khorramnia, A., \& Forutan, N. (2013). Silo effect a prominence factor to decrease efficiency of pharmaceutical industry". Iranian Journal of Pharmaceutical Research, 12, 207-216.

Walker, J. (2015). Three reason why we don't collaborate and how to change. Retrieved fromhttps://www.tennessean.com/story/opinion/columnists/2015/10/24/3-reasonswhy wedontcollaborate-and-how-change/74421462/ (accessed 25 June 2020).

Yan, E., Ding, Y., \& Zhu, Q. (2010). Mapping library and information science in China: A coauthorship network analysis. Scientometrics, 83(1), 115-131. https://doi.org/10.1007/s11192-009-0027-9

Yousef, A. (2010). Faculty attitudes towards collaboration with librarians. Library Philosophy and Practice (e-journal). 512. https://digitalcommons.unl.edu/libphilprac/512

Yu-Wei Chang. (2019) A comparison of researcher-practitioner collaborations in library and information science, education, and sociology. Journal of Librarianship and Information Science, 51(1), 208-217. https://doi.org/10.1177/0961000617726121 